\title{
Female Forensic Patients May Be an Atypical Sub-type of Females Presenting Aggressive and Antisocial Behavior
}

\author{
Sheilagh Hodgins ${ }^{1,2 *}$ \\ 1 Département de Psychiatrie et Addictologie, Université de Montréal, et Centre de recherche de l'Institut universitaire en \\ santé mentale de Montréal, Montreal, QC, Canada, ${ }^{2}$ Haina Forensic Psychiatric Institute, Haina, Germany
}

OPEN ACCESS

Edited by:

Hedvig Krona,

Lund University, Sweden

Reviewed by:

Alexander lan Frederic Simpson, Centre for Addiction and Mental Health (CAMH), Canada

Vivienne De Vogel,

De Forensische

Zorgspecialisten, Netherlands

*Correspondence:

Sheilagh Hodgins s.hodgins@umontreal.ca

Specialty section

This article was submitted to

Forensic Psychiatry

a section of the journal

Frontiers in Psychiatry

Received: 05 November 2021

Accepted: 17 January 2022

Published: 10 February 2022

Citation:

Hodgins S (2022) Female Forensic Patients May Be an Atypical Sub-type of Females Presenting Aggressive and

Antisocial Behavior.

Front. Psychiatry 13:809901

doi: 10.3389/fpsyt.2022.809901
The percentage of forensic psychiatric patients who are female varies from 5 to $13 \%$ in Europe, rises to $18 \%$ in England and Wales, and sits at 15\% in Canada. Similarly, many fewer women than men are incarcerated in correctional facilities. While these statistics supposedly reflect less antisocial and aggressive behavior (AAB) among females than males, not all findings support this supposition. Data from prospective longitudinal studies show that aggressive and antisocial behavior onsets in childhood, and in a small group of females it remains stable across the life-span. Unlike similar males, few of these females are convicted of crimes. This article begins with a review of descriptive studies of females sentenced by criminal courts to treatment in forensic psychiatric hospitals and moves on to present evidence showing that most female $A A B$ does not lead to criminal prosecution. Next, studies of female AAB are reviewed, noting that it onsets in early childhood and, that in a small group remains stable across the life-span. Subsequent sections of the article focus on the two most common mental disorders presented by female forensic patients, schizophrenia and borderline personality disorder, highlighting what is known about the sub-groups of women with these disorders who present AAB. The article concludes with recommendations for earlier identification by psychiatric services of women presenting mental disorders and $A A B$, treatments to reduce both the symptoms of their mental disorders and their life-long $A A B$, and the research that is needed in order to improve the effectiveness of these treatments. The real possibilities of prevention of the development of $A A B$, and even perhaps aspects of the mental disorders that plague female forensic patients, are described.

Keywords: antisocial and aggressive behavior, schizophrenia, borderline personality disorders, female, forensic psychiatry

\section{INTRODUCTION}

In most countries fewer women than men are treated within forensic psychiatric services and fewer are incarcerated in correctional facilities. While supposedly this reflects less antisocial behavior and aggressive behavior $(\mathrm{AAB})$ among women than men, not all findings support this supposition. Diagnostic studies report much higher rates of disorders that include symptoms of AAB among males than females, but this sex difference is not evident in prospective longitudinal studies of birth 
cohorts (1). For example, in a birth cohort of $\sim 1,000$ individuals followed to age $32,7.5 \%$ of females and $10.5 \%$ of males presented $\mathrm{AAB}$ that onset in childhood and remained stable through three decades of life (2). Female aggressive behavior is primarily indirect, reactive, and occurs within relationships $(3,4)$.

This article begins with a review of descriptive studies of females sentenced by criminal courts to treatment in forensic psychiatric hospitals and moves on to present evidence showing that most female $\mathrm{AAB}$ does not lead to criminal prosecution. Next, studies of female $\mathrm{AAB}$ are reviewed, noting that $\mathrm{AAB}$ onsets in early childhood and, that in a small group of females it remains stable across the life-span. Subsequent sections of the article focus on the two most common mental disorders presented by female forensic patients, schizophrenia and borderline personality disorder, highlighting what is known about the sub-groups of women with these disorders who present $\mathrm{AAB}$. The article concludes with recommendations for earlier identification by psychiatric services of women presenting $\mathrm{AAB}$ and treatments to reduce both the symptoms of their mental disorders and their life-long $\mathrm{AAB}$, and the research that is needed in order to improve the effectiveness of these treatments. The real possibilities of prevention of the development of $\mathrm{AAB}$, and even perhaps aspects of the mental disorders that plague female forensic patients, are described.

\section{FEMALE FORENSIC PSYCHIATRIC PATIENTS}

There are few females within forensic psychiatric services $(5,6)$ and in correctional facilities. Data reported from Belgium, Germany, Latvia, Italy, Ireland, Poland, Portugal, The Netherlands, England and Wales, Scotland, Slovenia, Spain, Finland, France, Croatia, Macedonia and Lithuania in 2013 reported that the prevalence of forensic inpatient beds varied from 1.4 per 100,00 inhabitants in Spain to 23.9 per 100,000 inhabitants in The Netherlands. The percentages of female patients varied from $5 \%$ in Slovenia to $18 \%$ in England and Wales (7). From 2002 to 2005, in Canada, $\sim 15 \%$ of forensic patients were female (8). In most countries, forensic hospitals treat primarily patients with psychotic disorders, however, The Netherlands has an additional forensic system specifically for patients presenting personality disorders.

A Dutch study (9) described a sample of 275 female forensic patients who were in their mid-thirties at the time of admission. Prior to admission, 54\% of the women had been convicted of a criminal offense, with a mean age at first conviction of 25 years and an average of four convictions, and $88 \%$ had been previously treated in psychiatric services. Just over three-quarters of the women had experienced maltreatment in childhood, 58\% were victimized as adults, and $44 \%$ of them both in childhood and adulthood. While $54 \%$ of the women had children, in $81 \%$ of these cases, the children been taken away by social services prior to admission. At the time of the index offense only two-thirds of the women had a home.

Index offenses included homicide (53.8\%), arson (23.1\%), other violence $(14.1 \%)$, property offenses $(6.4 \%)$, and sexual offenses (2.6\%). In $88 \%$ of cases, victims were involved with the perpetrator and notably there were 24 cases of maternal filicide, seven cases of physical abuse and four cases of sexual abuse of offspring (see also 4). Primary diagnoses included schizophrenia/psychotic disorder (32.9\%), substance use disorder (17.4\%), depression (12.9\%), and post traumatic stress disorder $(8.1 \%)$. Secondary diagnoses included borderline personality disorder (BOPD) (60.6\%) (with another $21 \%$ of patients presenting borderline traits), antisocial personality disorder (ASPD) (15.2\%) (with another 24\% presenting ASPD traits), and narcissistic personality disorder (2.6\%) (with another 9\% presenting narcissistic traits). Only three of the women obtained scores of 30 or higher on the Psychopathy ChecklistRevised (PCL-R), 19\% obtained scores of 23 or higher (a recommended cut-off score for women). The average PCL-R score was 16.5 .

During treatment, one-third of the women engaged in aggressive behavior primarily toward staff, and $45 \%$ in selfdestructive behavior. They were described by staff as being highly manipulative. The mean duration of treatment was 62 months.

Seventy-eight of these women were followed for a 3-year period following discharge (10) during which $18 \%$ died and $12 \%$ were re-admitted to psychiatric services. Death was associated negatively with interpersonal (facet 1 ) scores from the PCLR. Few recidivated, 14 by 3 years post-discharge and 24 at 11 years post-discharge. FAM total items, HCR-20 ${ }^{\mathrm{v} 3}$, clinical items, and START vulnerability scores showed the highest predictive accuracy. Only six women were convicted of violent crimes in the 3 years following discharge, and 14 during 11 years postdischarge. These latter violent convictions were predicted only by HCR-20 ${ }^{\mathrm{v} 3}$ clinical scores and START vulnerabilities score (10).

Another study (11) examined all forensic psychiatric patients in Sweden in 2010, 15\% of whom were women aged, on average, 41 years. Prior to admission, $85 \%$ of these women had previously been inpatients in psychiatric services, 51\% had records of criminal convictions, and $25 \%$ convictions for violence. At the time of admission to forensic services, 39\% of the women were homeless. Almost half (48\%) of the women were diagnosed with schizophrenia spectrum disorders, $9 \%$ with mood disorders, and $17 \%$ with personality disorders. Most index offenses included some form of violence; $43 \%$ crimes related to life and death (e.g., murder, manslaughter, assault), $28 \%$ general dangerous crimes (e.g., arson, threat, violence against staff), and 12\% liberty and peace (e.g., trafficking, trespassing).

A study in Ontario, Canada of all forensic admissions from 1987 to 2012 resulting in a disposition of Not Criminally Responsible on account of Mental Disorder reported that $14 \%$ (362) were women (12). Prior to this admission to forensic services, $91 \%$ of the women had been treated in psychiatric services, $65 \%$ as inpatients, and $36 \%$ had been convicted of crimes. At the time of the index offense, these women were aged, on average, 39 years, $13 \%$ of them were homeless, $42 \%$ had not graduated from high school, and $21 \%$ were employed. More than half $(58 \%)$ of the index offenses were described as violent and $19 \%$ as serious violence. More than three-quarters (77\%) of the women were diagnosed with a psychotic disorder, and $22 \%$ with mood disorders. Comorbid substance use disorders were 
reported among 29\% and indications of personality disorders among $27 \%$. Another Canadian study provides a similar picture of female forensic patients (13).

Thus, female forensic psychiatric patients present mental disorders that include dysfunctions of emotion and cognition and low levels of psychosocial functioning, most commonly schizophrenia and BOPD, in addition to long histories of AAB and often, psychopathic traits. Most were treated in general psychiatric services before committing the crime that lead to admission to forensic services.

\section{FEMALE AAB IS HIDDEN FROM THE CRIMINAL JUSTICE SYSTEM}

Among females presenting $\mathrm{AAB}$, forensic patients are distinguished by having been prosecuted in the criminal justice system. Findings from a prospective longitudinal investigation, suggest that despite a long history of $\mathrm{AAB}$, many women escape prosecution. The Dunedin Multidisciplinary Health and Development Study followed a birth cohort of $\sim 500$ males and 500 females for more than 40 years, with repeated assessments of behavior, cognition, mental and physical health. At age 32, the males and females characterized by childhood onset $A A B$ were engaging in serious violence and experiencing significant mental health, physical health, and economic problems. A greater proportion of the males (33\%) than the females $(3 \%)$ had been convicted of violent crimes, but $42 \%$ of the women and $10 \%$ of the males reported hitting a child. While $11.1 \%$ of the women reported engaging in violence toward others, informants reported that $47.1 \%$ of them had in fact engaged in such violence. Among the males, 30.6\% self-reported engaging in violence, and informants reported that $26.7 \%$ had engaged in violence (2). Similarly, in a study of forensic patients in The Netherlands, the women had twice as many police contacts without convictions than the men (14). These findings, and others (3) strongly indicate that neither records of arrests or convictions fully capture $\mathrm{AAB}$, especially among females. Women in forensic and correctional facilities may thereby represent a small, atypical, sub-group of females presenting AAB. Importantly, criminal prosecution is influenced by many factors aside from the accused's behavior. Consequently, studies measuring aggressive behavior are more likely to identify both etiological factors for $\mathrm{AAB}$ among females and factors promoting prevention and treatment.

We studied 96 teenage girls who consulted a clinic for substance misuse treatment, and their 89 mothers and 52 fathers (15). Forty-three (44.8\%) girls reported engaging in at least one violent act (street fight; carried weapon; beaten someone; hurt someone with a weapon). Almost two-thirds (62.8\%) of the violent girls and $34.0 \%$ of the non-violent were diagnosed with conduct disorder. Univariate comparisons showed that the violent girls, compared to the non-violent, were four times more likely to have a first degree relative with a substance use disorder, three times more likely to have a substance use disorder, three times more likely to have been abused by their mother, three times more likely to have been abused by peers, and two times more likely to have been sexually abused. The violent girls were characterized by significantly more risk factors than the nonviolent girls. Protective factors for violence included maternal warmth, attachment, and parents' attempted understanding.

We followed the girls who had presented conduct disorder for 5 years. At a mean age of 24 years, very few of them met criteria for Antisocial Personality Disorder (ASPD), although they reported significantly higher rates of aggressive behavior than a matched sample of healthy women. Few had graduated from high school, 59\% were unemployed, and 48\% had given birth on average 10 years earlier than women in Stockholm. Brain scans showed that the women with a history of childhood conduct disorder, as compared to the healthy women, displayed abnormalities of gray and white matter structures even after adjusting for past and current comorbid disorders and maltreatment $(16,17)$. Both in adolescence and adulthood, the women with prior conduct disorder showed higher levels of psychopathic traits than the healthy women but lower than scores reported for female offenders. Yet, psychopathic traits were associated with abnormalities of neural white matter structures, and notably, the interpersonal facet (glibness, grandiosity, and manipulation) was associated with a white matter abnormality previously observed in adult male offenders presenting the syndrome of psychopathy (18). Thus, in females, conduct disorder prior to age 15 was associated with aggressive behavior from childhood onwards, low academic achievement, by midadolescence psychopathic traits higher than levels reported among healthy women that stayed stable for the next 5 years, unemployment, early child birth, neural abnormalities of both gray and white matter, but not diagnoses of ASPD. Thus, female $\mathrm{AAB}$ as previously noted remains hidden from view, even though these girls/women display abnormalities of brain structure and functioning (19), endure physical and sexual victimization, hurt others, and fail to support themselves and their offspring.

\section{AAB ONSETS VERY EARLY IN LIFE}

A recent review of aggressive behavior stated: "Men are found to use aggression more than females when studies focus on direct forms of aggression (e.g., physical or verbal aggression) and when the target of the aggression is an individual not known to the perpetrator. Conversely, females are found to use aggression more often than males when studies focus on indirect forms of aggression (e.g., psychological or social aggression) and when the target of the aggression is an individual known to the perpetrator" (20). Robust evidence from prospective, longitudinal investigations of birth and population cohorts conducted in different countries confirm that aggressive behavior is observed during the first year of life, that it increases to about the age of 4 years, then declines. All studies identify one group of individuals who display high levels of aggressive behavior through childhood, adolescence, and adulthood (20). In a representative sample of 1,183 Canadian children $12.5 \%$ of boys and $11.0 \%$ of girls were reported to present the highest levels of aggressive behavior and of indirect aggression from ages 2 to 8 years. Another $1 \%$ of boys and $<0.63 \%$ girls presented high 
aggressive behavior without indirect aggression and $0.18 \%$ of boys and $1 \%$ of girls presented indirect aggression with aggressive behavior (21). These same data showed that from 2 years of age onwards, among those presenting high, stable, aggressive behavior, there were more boys (53.6\%) than girls (46.4\%). From age 4 years, more girls (57.6\%) than boys (42.7\%) were on a high trajectory of indirect (relational) aggression. While trajectories of aggressive behavior remained relatively stable through adolescence, there was a large increase in the proportions of teenagers engaging in relational aggression. There is now a large body of evidence regarding bullying by both boys and girls (22). Other studies report that from toddlerhood through adolescence ( $\sim 5 \%$ of boys display high levels of physically aggressive behavior as do $1 \%$ of girls (23); for a review see (24). As for all types of aggressive behavior, across adolescence, stable high trajectories of both proactive and reactive aggression have been observed (20).

In the Dunedin study (25), comparisons were made of the males and females who presented conduct problems in childhood and whose $\mathrm{AAB}$ persisted across the life-span. At age three, within sex comparisons showed that those who presented early onset, persistent, conduct problems differed from other cohort members by displaying more neurological soft signs, and lower scores on the Bailey Motor Test, and in childhood lower IQ and reading scores. Boys, not girls, characterized by early onset, persistent, conduct problems also presented lower heart rate, uncontrolled temperament, and poor memory. From age 7 to 15 years, both females and males with childhood onset, persistent, conduct problems differed from same sex healthy peers as to three individual factors-low IQ, poor reading achievement, and ADHD symptoms, and seven parent characteristics-low socio-economic status, maltreatment and inconsistent parenting, family conflict, poor maternal mental health, low maternal IQ, and parents' criminality. Thus, individual and family risk factors for early onset conduct problems that remained stable across the life-span were mostly similar in males and females.

Callous-unemotional traits, a key antecedent of psychopathy traits, can be identified by age 2 or 3 years. At even younger ages, precursors of callous-unemotional traits are observed (2628). Among toddlers, callous-unemotional traits are reduced by warm, positive maternal parenting. If not lowered, these traits provoke harsh parenting in the subsequent years that promotes AAB. A study of a randomly selected population sample in the UK estimated that close to half of both the girls and boys with conduct disorder presented elevated levels of callousunemotional traits (29). These children were five times more likely than others with conduct disorder to show serious conduct problems 3 years later. Prevalence rates for elevated levels of CU traits have ranged from 10 to $32 \%$ in community samples and $21 \%$ to $50 \%$ in clinic-referred samples of children with conduct problems (30). Thus, while CU is observed by age 2 or 3 years, and predictors of CU by six or seven months of age, CU shows change during childhood, but stability in a small group. By adolescence, levels of psychopathic traits appear to be relatively consolidated in both males and females (31).

In a study of a large UK population sample of 9,462 twins, trajectory analyses of callous-unemotional traits rated by teachers at age 7,9 , and 12 years found that $3.4 \%$ of the children presented high stable callous-unemotional traits. Nineteen percent of these children were girls. The sub-group displaying high and stable callous-unemotional traits showed the highest levels of conduct problems prior to school entry and by early adolescence their families were described as chaotic, and their parents were using negative discipline (32). The moderate stability and resistance to change of callous-unemotional traits from age 7 to 17 was shown in a study of boys. Only eight of 65 family and individual factors that were examined modified stability of callous-unemotional traits, but only among boys with low, not high, psychopathy scores at age 13 (33).

The stability of conduct problems and callous-unemotional traits is further shown by a US study in which a large sample of US children, at age three, were divided into four groups: 1. no conduct problems, no callous-unemotional traits, no internalizing symptoms; 2. conduct problems alone; 3. conduct problems with callous-unemotional traits; and 4. conduct problems with callous-unemotional traits and internalizing problems. Membership in these groups remained stable up to age 15 (34). This study found no sex differences in the proportions of girls in the four groups. By contrast, other studies of children suggest that more girls than boys present conduct problems, callous-unemotional traits and anxiety, while studies of adolescents suggest that the group with conduct problems and callous-unemotional traits and low anxiety includes few females (34).

Children presenting conduct problems together with callous-unemotional traits and anxiety show heightened threat perception, and greater autonomic and central nervous system reactivity that triggers reactive aggression (35), and have more often experienced maltreatment than children presenting conduct problems and callous-unemotional traits but not anxiety (35-37). Further, changes in autonomic system reactivity following maltreatment vary as a function of callousunemotional traits (35). Children presenting conduct problems, callous-unemotional traits, and anxiety are fearful, hypersensitive to threat (38), obtain lower than average intelligence scores, do poorly at school, show weak self-regulation (34), and present no deficits in recognizing or responding to emotional expressions $(38,39)$, despite being more behaviourally and emotionally dysregulated (38).

Importantly, conduct problems and callous-unemotional traits in young girls predict criminality. In a prospective study of 1,241 girls, we found that those rated by their teachers at age 6 as showing conduct problems and callous-unemotional traits were six times more likely than girls without such ratings to be convicted of a non-violent crime by age 24 , and those rated by their teachers as presenting callous-unemotional traits with or without conduct problems at age 10 were four times more likely to be convicted of non-violent crimes by age 24 (40).

Taken together, this evidence suggests that women sentenced to forensic psychiatric services may have a life-long history of $\mathrm{AAB}$ and the callous-unemotional traits of psychopathy. They have endured physical and sexual maltreatment, done poorly at school and in the job market, had multiple intimate relationships often with men presenting $\mathrm{AAB}$ and at a young age given birth 
to children who are at risk for $\mathrm{AAB}$ from a young age. The $A A B$ may often have been in response to real or perceived threat or to curry favor with friends or to achieve some other goal. Treatments and management strategies aimed at reducing $\mathrm{AAB}$ by these women are, in fact, tackling a life-long pattern of behavior and personality.

\section{MENTAL DISORDERS PRESENTED BY FEMALE FORENSIC PSYCHIATRIC PATIENTS}

\section{Schizophrenia}

While studies of forensic psychiatric samples show that most risk factors for violence are similar in males and females, for example similar prevalence of childhood conduct problems (41), clinical factors are more strongly linked to aggressive behavior in females $(3,4)$. Yet, studies of female forensic patients have not generally focused on aspects of their mental disorders that may be linked to AAB. Schizophrenia is a potent risk factor for violent offending among both females and males (41). While fewer women than men with schizophrenia commit crimes, schizophrenia increases the risk of violent offending to a greater extent among females than males. For example, we examined a birth cohort composed of all the 358,180 persons born in Denmark from 1944 through 1947 followed until they were in their mid-forties. Official criminal records indicated that the risk of a violent crime was elevated 23.2 (14.4-37.4) times among the women with schizophrenia treated in psychiatric services as compared to women never admitted to a psychiatric ward, a much greater increase than that of five found among males (42). These findings suggest that schizophrenia confers a very elevated risk for violence in females. In other words, very few females are convicted of a violent crime, but among those few who develop schizophrenia a much larger proportion are convicted of a violent crime. However, the etiology of AAB among women with schizophrenia may be the same as it is for men with schizophrenia.

As presented in Table 1, comparisons of criminal convictions of women hospitalized in general psychiatry with diagnoses of severe mental illness (primarily schizophrenia) and general population samples of women in the UK, Sweden, and Denmark, again shows that the increase in risk conferred by illness is much greater for females than males. Severe mental illness was associated with a 17 fold increase in risk of a conviction for a violent crime in the UK, 11 fold in Sweden, and 6 fold in Denmark (43). But as noted, many incidents of aggressive behavior, particularly among women, do not lead to criminal prosecution. For example, using the definitions of aggressive behavior and serious violence from the MacArthur study of violence (44), we examined aggressive behavior of females in three different studies that were similar as to age and that had used the same instrument to collect information on aggressive behavior and violence (43). In a UK sample of inpatients with severe mental illness (primarily schizophrenia) 39\% had engaged in aggressive behavior and 19\% in serious violence (43) in the past 6 months, in a trial of antipsychotic medications that recruited only stable patients with schizophrenia, $21 \%$ had engaged in aggressive behavior and 3\% violence in the past 6 months (44), and among the patients with schizophrenia in the MacArthur Violence study $44 \%$ reported aggressive behavior and $18 \%$ violence in the past 10 weeks (43). Even prior to first admission for psychosis, approximately one-third of patients are reported to have engaged in aggressive behavior (45). A metaanalysis reported that male sex was associated with any violence, but there was no sex-difference when examining incidents of serious violence (46). People with schizophrenia are at high risk for physical victimization, more so if they are engaging in aggressive behavior (47). The risk of such victimization varies across countries (48).

Thus, while fewer women than men, with schizophrenia, are convicted of crimes and engage in aggressive behavior toward others, schizophrenia confers a greater risk for offending and for aggressive behavior among women than among men. This finding may suggest that schizophrenia symptoms and the associated features such as cognitive, emotional, and psychosocial functioning, are more related to aggressive behavior in women than men. Further, this finding implies that the effective treatment of all aspects of the illness is needed in order to reduce aggressive behavior.

People who develop schizophrenia present multiple difficulties from early childhood onwards. By age two, they show motor abnormalities such as delays in walking and talking and specific neurological soft signs (49), in the subsequent years there is further evidence of motor deficiencies, neurological signs, receptive language deficits (50), lower than average IQ (51), and by mid-childhood psychotic-like-experiences (52). Additionally, a significant minority present conduct disorder. These children are more likely than healthy children to experience maltreatment by adults and by peers (53). Prospectively collected data indicate that $40 \%$ of individuals who develop schizophrenia presented conduct problems in childhood (54), while retrospectively collected data from samples of women and men with schizophrenia report that $\sim 20 \%$ had a history of conduct problems since childhood. Some estimates among male patients with severe mental illness are as high as $42 \%$ presenting childhood onset conduct problems (43). We found that among males, symptoms of conduct disorder were linearly, and positively associated with numbers of convictions for any crime and for violent crimes after controlling for substance misuse (55). In a sample of male and female patients with severe mental illness, we found no sex difference in the link between childhood/adolescent conduct disorder and crime or aggressive behavior after controlling for substance misuse (56).

Females who are developing schizophrenia are hidden among adolescents presenting AAB. For example, we conducted a follow-up study of 1660 males and 332 females who had been treated at the only clinic for adolescent substance misuse in a large urban center in Sweden from 1968 to 1971 . When they consulted the clinic, one-third of the females had not used illicit drugs, two-thirds had used alcohol only experimentally or not at all, and $61 \%$ had no record of delinquency. Statistics Sweden created a general population sample by randomly selecting for each individual in this clinical sample an individual in the 
TABLE 1 | Odds ratios for criminal convictions up to age 30 comparing inpatient samples with severe mental illness to general population samples from three countries.

\begin{tabular}{lccc}
\hline & $\begin{array}{c}\text { UK inpatient sample } \\
\text { compared to UK general } \\
\text { population sample }\end{array}$ & $\begin{array}{c}\text { Swedish inpatient sample } \\
\text { compared to Swedish } \\
\text { population sample }\end{array}$ & $\begin{array}{c}\text { Danish inpatient sample } \\
\text { compared to Danish } \\
\text { population sample }\end{array}$ \\
\hline $\begin{array}{l}\text { Men } \\
\text { Conviction for a criminal offense }\end{array}$ & $2.72(1.90-3.90)$ & 2.15 & $(1.39-3.33)$ \\
Conviction for a violent criminal offense & $4.86(3.30-7.16)$ & 4.74 \\
Women & $2.85(1.63-4.98)$ & $(2.84-7.91)$ \\
Conviction for a criminal offense & $17.24(8.18-36.32)$ & 3.78 \\
Conviction for a violent criminal offense & & $(2.13-6.69)$ \\
\end{tabular}

A. General population statistics available from Chapter 3 of Home Office's 'Criminal careers of those born between 1953 and 1978' document, available from http://www.homeoffice. gov.uk/rds/pdfs/hosb401.pdf.

B. Hodgins S. Mental disorder, intellectual deficiency, and crime. Evidence from a birth cohort. Arch Gen Psychiatry (1992) 49:476-83. doi: 10.1001/archpsyc. 1992.01820060056009.

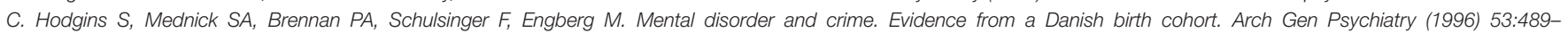
96. doi: 10.1001/archpsyc.1996.01830060031004.

Odds ratios were calculated from data as article presents relative risk ratios.

Table from: (3)

general population with the same sex, month, year, and place of birth. All participants were followed to the age of 50 using national health, criminal, and social service registers. Among the females in the clinical sample compared to those in the general population sample, the risk (expressed as odds ratio) of developing schizophrenia was $8.55(2.55-28.66)$ by age 50 , much higher than the risk for males 3.79 (2.38-6.05) (57). A similar analysis of younger sample lead to the same results (58).

Thus, by the time a women presenting schizophrenia is admitted to a forensic psychiatric service she typically has a long history of motor, cognitive, and emotional difficulties, and most will also have a history of AAB.

Studies have shown that elevated positive psychotic symptoms during an acute episode, for example at admission to a psychiatric ward, are associated with aggressive behavior in almost all patients. When patients take antipsychotic medication, psychotic symptoms decline as does the aggressive behavior. For example, one study of inpatients included 67 female and 155 male patients with schizophrenia or bipolar disorder. There was no difference in chlorpromazine equivalents of antipsychotic medications taken by the women and men. Thirty-one percent of the women and $43 \%$ of the men engaged in physical assaults in the 2 months after admission. Women tended to have a higher total number of physical assaults than men during the initial month after admission, and a faster decrease in assaults during the second month. Although $41 \%$ of the males had engaged in aggressive behavior in the community prior to admission, this was true of only $25 \%$ of the women (59).

When positive symptoms are lowered by antipsychotic medication, other factors such as an early onset pattern of AAB emerges as the one of the strongest predictors and correlates of AAB (60-62). However, positive psychotic symptoms and aggressive behavior are intricately linked in ways that still elude understanding. A recent randomized controlled trial measured the effects of different antipsychotic medications on positive symptoms and aggressive behavior of men with schizophrenia, half of whom presented a history of AAB since childhood. Among violent patients with schizophrenia, those with conduct disorder prior to age 15 , as compared to those without this past disorder, showed greater reductions in aggressive behavior and similar reductions in positive symptoms when taking clozapine as compared to haloperidol. Similarly, a stronger lowering of aggressive behavior was shown among patients with than without prior conduct disorder when taking olanzapine as compared to haloperidol (63). Interestingly, the medication, clozapine, that was most effective in lowering both positive symptoms and aggressive behavior among the men with schizophrenia and a childhood history of AAB, impacts the neurotransmitter serotonin that is strongly linked to aggressive behavior (64). Further, among men with schizophrenia, those with a childhood onset of $\mathrm{AAB}$ present distinctive neural differences as compared to those with no childhood history of $\mathrm{AAB}$ and some neural characteristics similar to men without schizophrenia with a childhood history of AAB (65). There are no similar studies of females with schizophrenia who present AAB. However, since neither the etiology of schizophrenia (66) nor AAB (67) varies by sex, it is likely that neural abnormalities observed among men presenting schizophrenia and $\mathrm{AAB}$ also characterize women with schizophrenia and AAB. More knowledge of the interplay of aspects of schizophrenia and $\mathrm{AAB}$ from early childhood onwards is urgently needed.

\section{Borderline Personality Disorder}

As noted above, another disorder commonly diagnosed among female forensic patients is BOPD. The prevalence of BOPD is estimated at $0.7 \%$ to $2.3 \%$ with most studies reporting a similar prevalence in women and men, but much higher treatment seeking among women (68). Reactive aggressive behavior is recognized as a key feature of BOPD. The aggressive behavior of persons with BOPD is reported to be associated with affective 
dysregulation, impulsivity, threat hypersensitivity, and empathic functioning and the associated neurobiological abnormalities (69). Women, like men with BOPD, also display traits of psychopathy $(70,71)$ and/or ASPD $(72)$ that are associated with aggressive behavior. Thus, some of the mechanisms underlying aggressive behavior among women presenting BOPD may be directly related to $\mathrm{BOPD}$, while others are associated with traits of ASPD and psychopathy. The key to understanding the etiology of aggressive behavior among women with BOPD, and to identify effective treatments, risk management strategies, and prevention programs, may be furthering knowledge of the disorder itself.

As with females presenting $\mathrm{AAB}$ and those who develop schizophrenia, by the time women with BOPD are admitted to a forensic psychiatry service, they have a long history of difficulties. For example, in a prospective, longitudinal study of 2,232 British twins, at age 12, mothers rated items tapping three core features of adult BOPD: affective instability/dysregulation, impulsivity/behavioural dysregulation, and disturbed relatedness/interpersonal dysfunction. The children who obtained scores at the $95^{\text {th }}$ percentile or higher of the cohort on the borderline personality disorder items were characterized by lower IQs, less well developed theory of mind, low self-control, high levels of impulsivity and externalizing and internalizing problems, and were seven times more likely than the children without these high scores to have experienced maltreatment. They were also more likely than the children without the borderline symptoms to present conduct disorder, depression, anxiety, and psychotic symptoms (73). By age 18, they presented a distinct personality characterized by narrowmindedness, antagonism, distress, and poor impulse control, and elevated risks for conduct disorder, alcohol use disorder, cannabis use disorder, depression, generalized anxiety disorder, post-traumatic stress disorder, and suicide attempts or self-harm. Not surprisingly given these disorders, they had acquired low educational qualifications, were neither studying or working, smoked, were socially isolated, reported low life satisfaction, had records of criminality, and more physical and sexual maltreatment and crime victimization (74).

Another prospective longitudinal study of 2,450 US adolescent girls assessed clinical, psychosocial, and demographic factors, previously found to be associated with BOPD in late childhood, early and mid-adolescence. Nineteen predictors assessing depressive and anxiety symptoms, self-control, harsh punishment, and poor social and school functioning explained $33.2 \%$ of the variance in BOPD symptoms. Factors were identified that distinguished BOPD from conduct disorder and depression (75).

Thus, when women with BOPD are sentenced to forensic psychiatric treatment, they present a long history of emotional dysregulation, conduct problems, lower than average cognitive abilities, failure at school and at work, AAB, and criminality.

\section{THE ROLE OF MALTREATMENT}

As reviewed above, young girls presenting $\mathrm{AAB}$, and those developing schizophrenia or BOPD are at elevated risk for physical and sexual maltreatment by adults and peers. The high risk of victimization persists through adulthood. A Swedish study included 34,903 persons with schizophrenia, 29,692 with bipolar disorder, and a comparison group of 2,763,012 Swedish citizens without these disorders. Six "triggers" of violence were assessed: exposure to violence, parental bereavement, self-harm, traumatic brain injury, unintentional injuries, and substance intoxication. Within individual analyses were conducted to determine whether the "triggers" occurred in the week preceding the commission of a violent crime. The triggers were all associated with an increased risk of violent crime in each group, most strongly among persons with schizophrenia. The trigger most strongly associated with committing a violent crime was violent victimization that increased the risk of violent crime in the following week, 12 times among people with schizophrenia, and eight times among people with bipolar disorder and also among those in the comparison group (76). Aggressive behavior is strongly associated with physical victimization highlighting a vicious circle that likely onsets in childhood and persists across the life-span.

\section{CONCLUSION}

There are few women in forensic psychiatric hospitals. They suffer from severe mental disorders that are associated with difficulties in multiple domains of functioning accompanied by $\mathrm{AAB}$ from early childhood onwards. While most females presenting a life-long history of $\mathrm{AAB}$ escape criminal prosecution, the few in forensic psychiatry did not. When they are admitted to general psychiatric services, little, if anything is done to assess, manage, and/or reduce their AAB. Yet, effective treatment at first episode for psychosis could prevent much suffering and harm to others. Knowledge is urgently needed to identify treatments that effectively reduce the symptoms of their mental disorders, increase their level of psychosocial functioning, and reduce their AAB. The research strategy most likely to provide knowledge that would improve the effectiveness of treatment for such women would focus on studies of clinical samples of females with schizophrenia or with BOPD, comparing those with and without AAB. Such studies also have the potential to yield findings about the association of the mental disorder symptoms and AAB.

Current evidence strongly suggests that the factors associated with the mental disorders of women who end up in forensic services are intricately connected with their AAB across developmental stages. The available evidence also shows that the antecedents of these women's mental disorders and AAB emerge very early in life. Aggressive behavior and callous-unemotional traits, motor and language delays, low IQ, emotion dysfunction, and parents presenting $\mathrm{AAB}$ and/or mental health problems providing harsh and ineffective parenting are evident prior to school entry such that by age six regular classroom teachers can identify those at elevated risk of adult criminality. Findings from prospective, longitudinal studies already provide a wealth of evidence that could be used to inform childhood prevention programs. Interventions that succeeded in reducing aggressive behavior, impulsivity, and emotion dysregulation in childhood would allow for greater academic success, despite lower than average intelligence, and interventions in early adolescence could 
prevent substance misuse that would increase the likelihood of completing work training and employment.

Although $\mathrm{AAB}$ by females is hidden from view, the consequences for children and others cared for by women, such as the elderly, are substantial and destructive. These women play a critical role in the intergenerational transfer of antisocial behavior as shown by the fact that their offspring present an elevated risk of $\mathrm{AAB}$ (77). Females who present $\mathrm{AAB}$ disproportionately mate with antisocial males, give birth at a young age, transmit genes that confer vulnerability for antisocial behavior, provide harsh parenting and other adverse rearing conditions to their offspring (77). Thus, preventing the development of women who are treated in forensic psychiatric services will take several generations. Interventions aimed at reducing teen pregnancy would contribute to achieving this objective. Parents who themselves present antisocial and/or aggressive behavior are at increased risk to engage in non-optimal parenting (78), and to physically maltreat their children $(24,78-$

\section{REFERENCES}

1. Hodgins S, Checknita D, Lindner P, Schiffer BA, De Brito S. Antisocial personality disorder. In: Beech AR, Carter AJ, Mann RE, Rotshtein P, editors. The Wiley Blackwell Handbook of Forensic Neuroscience. John Wiley \& Sons (2018). p. 229-71. doi: 10.1002/9781118650868.ch10

2. Odgers CL, Moffitt TE, Broadbent JM, Dickson N, Hancox RJ, Harrington $\mathrm{H}$, et al. Female and male antisocial trajectories: from childhood origins to adult outcomes. Dev Psychopathol. (2008) 20:673-716. doi: 10.1017/S0954579408000333

3. Vogel V de, Nicholls TL. Gender matters: an introduction to the special issues on women and girls. Int J Forensic Ment Health. (2016) 15:125. doi: 10.1080/14999013.2016.1141439

4. Vogel V de, Spa E de. Gender differences in violent offending: Results from a multicentre comparison study in Dutch forensic psychiatry. Psychol Crime Law. (2019) 25:739-51. doi: 10.1080/1068316X.2018.1556267

5. Girolamo G de, Iozzino L, Ferrari C, Gosek P, Heitzman J, Salize HJ, et al. A multinational case-control study comparing forensic and non-forensic patients with schizophrenia spectrum disorders: the EU-VIORMED project. Psychol Med. (2021) 1-11. doi: 10.1017/S0033291721003433

6. Hodgins S, Müller-Isberner R, Freese R, Tiihonen J, Repo-Tiihonen E, Eronen $\mathrm{M}$, et al. A comparison of general adult and forensic patients with schizophrenia living in the community. Int J Forensic Ment Health. (2007) 6:63-75. doi: 10.1080/14999013.2007.10471250

7. Tomlin J, Lega I, Braun P, Kennedy HG, Herrando VT, Barroso R, et al. Forensic mental health in Europe: some key figures. Soc Psychiatry Psychiatr Epidemiol. (2021) 56:109-17. doi: 10.1007/s00127-020-01909-6

8. Crocker AG, Nicholls TL, Seto MC, Charette Y, Côté G, Caulet M. The national trajectory project of individuals found not criminally responsible on account of mental disorder in Canada. Part 2: The people behind the label. Can J Psychiatry. (2015) 60:106-16. doi: 10.1177/07067437150 6000305

9. De Vogel V, Stam J, Bouman YH, Ter Horst P, Lancel M. Violent women: a multicentre study into gender differences in forensic psychiatric patients. J Forens Psychiatry Psychol. (2016) 27:145-68. doi: 10.1080/14789949.2015.1102312

10. Vogel V de, Bruggeman M, Lancel M. Gender-sensitive violence risk assessment: predictive validity of six tools in female forensic psychiatric patients. Crim Justice Behav. (2019) 46:528-49. doi: 10.1177/0093854818824135

11. Degl' Innocenti A, Hassing LB, Lindqvist A-S, Andersson H, Eriksson L, Hanson FH, et al. First report from the Swedish national forensic psychiatric register (SNFPR). Int J Law Psychiatry. (2014) 37:2317. doi: 10.1016/j.ijlp.2013.11.013
80). When children are born to young women with histories of $\mathrm{AAB}$, nurse visitation programs can identify mothers who would benefit from parenting programs that reduce conduct problems in their offspring.

Public and mental health policies that allow females to develop such profound disorders and to harm so many victims before sentencing them to forensic care are cruel and wasteful. Science can contribute to prevention and to the reduction of suffering.

\section{AUTHOR CONTRIBUTIONS}

The author confirms being the sole contributor of this work and has approved it for publication.

\section{FUNDING}

This work was supported by the Haina Institute of Forensic Psychiatry.

12. Penney SR, Seto MC, Crocker AG, Nicholls TL, Grimbos T, Darby PL, et al. Changing characteristics of forensic psychiatric patients in Ontario: a population-based study from 1987 to 2012. Soc Psychiatry Psychiatr Epidemiol. (2019) 54:627-38. doi: 10.1007/s00127-018-1619-6

13. Nicholls TL, Crocker AG, Seto MC, Wilson CM, Charette Y, Côté G. The national trajectory project of individuals found not criminally responsible on account of mental disorder. Part 5: How essential are gender-specific forensic psychiatric services? Can J Psychiatry. (2015) 60:13545. doi: 10.1177/070674371506000308

14. Vogel V de, Lancel $M$. Gender differences in the assessment and manifestation of psychopathy: Results from a multicenter study in forensic psychiatric patients. Int J Forensic Ment Health. (2016) 15:97110. doi: 10.1080/14999013.2016.1138173

15. Oliver BR, Hodgins S. Understanding Violence in Girls with Substance Misuse Problems. In: Andershed A-K, editor. Girls at Risk. New York, NY: Springer New York (2013). p. 79-104. doi: 10.1007/978-1-4614-4130-4_5

16. Budhiraja M, Pereira JB, Lindner P, Westman E, Jokinen J, Savic I, et al. Cortical structure abnormalities in females with conduct disorder prior to age 15. Psychiatry Res Neuroimaging. (2019) 289:37-44. doi: 10.1016/j.pscychresns.2018.12.004

17. Lindner P, Savic I, Sitnikov R, Budhiraja M, Liu Y, Jokinen J, et al. Conduct disorder in females is associated with reduced corpus callosum structural integrity independent of comorbid disorders and exposure to maltreatment. Transl Psychiatry. (2016) 6:e714. doi: 10.1038/tp.2015.216

18. Lindner P, Budhiraja M, Westerman J, Savic I, Jokinen J, Tiihonen J, et al. White matter correlates of psychopathic traits in a female community sample. Soc Cogn Affect Neurosci. (2017) 12:1500-10. doi: 10.1093/scan/nsx070

19. Freitag CM, Konrad K, Stadler C, Brito SA de, Popma A, Herpertz SC, et al. Conduct disorder in adolescent females: current state of research and study design of the FemNAT-CD consortium. Eur Child Adolesc Psychiatry. (2018) 27:1077-93. doi: 10.1007/s00787-018-1172-6

20. Tremblay RE, Vitaro F, Côté SM. Developmental origins of chronic physical aggression: a bio-psycho-social model for the next generation of preventive interventions. Annu Rev Psychol. (2018) 69:383-407. doi: 10.1146/annurev-psych-010416-044030

21. Côté SM, Vaillancourt T, Barker ED, Nagin D, Tremblay RE. The joint development of physical and indirect aggression: predictors of continuity and change during childhood. Dev Psychopathol. (2007) 19:3755. doi: 10.1017/S0954579407070034

22. Kljakovic M, Hunt C, A. meta-analysis of predictors of bullying and victimisation in adolescence. J Adolesc. (2016) 49:13445. doi: 10.1016/j.adolescence.2016.03.002

23. Broidy LM, Tremblay RE, Brame B, Fergusson DM, Horwood JL, Laird $\mathrm{R}$, et al. Developmental trajectories of childhood disruptive behaviors and 
adolescent delinquency: a six-site, cross-national study. Dev Psychol. (2003) 39:222-45. doi: 10.1037/0012-1649.39.2.222

24. Tremblay RE, Côté SM. Sex differences in the development of physical aggression: an intergenerational perspective and implications for preventive interventions. Infant Ment Health J. (2019) 40:129-40. doi: 10.1002/imhj.21760

25. Moffitt TE, Caspi A. Childhood predictors differentiate life-course persistent and adolescence-limited antisocial pathways among males and females. Dev Psychopathol. (2001) 13:355-75. doi: 10.1017/S0954579401002097

26. Dadds MR, Allen JL, Oliver BR, Faulkner N, Legge K, Moul C, et al. Love, eye contact and the developmental origins of empathy v. psychopathy. Brit $J$ Psychiatry. (2012) 200:191-6. doi: 10.1192/bjp.bp.110.085720

27. Hyde LW, Shaw DS, Gardner F, Cheong J, Dishion TJ, Wilson MN. Dimensions of callousness in early childhood: links to problem behavior and family intervention effectiveness. Dev Psychopathol. (2013) 25:34763. doi: 10.1017/S0954579412001101

28. Waller R, Gardner F, Hyde LW, Shaw DS, Dishion TJ, Wilson MN. Do harsh and positive parenting predict parent reports of deceitful-callous behavior in early childhood? J Child Psychol Psychiatry. (2012) 53:94653. doi: 10.1111/j.1469-7610.2012.02550.x

29. Rowe R, Maughan B, Moran P, Ford T, Briskman J, Goodman R. The role of callous and unemotional traits in the diagnosis of conduct disorder. J Child Psychol Psychiatry. (2010) 51:688-95. doi: 10.1111/j.1469-7610.2009.02199.x

30. Frick PJ, Ray JV, Thornton LC, Kahn RE. Can callous-unemotional traits enhance the understanding, diagnosis, and treatment of serious conduct problems in children and adolescents? A comprehensive review. Psychol Bull. (2014) 140:1-57. doi: 10.1037/a0033076

31. Hemphälä M, Kosson DS, Westerman J, Hodgins S. Stability and predictors of psychopathic traits from mid-adolescence through early adulthood. Scand J Psychol. (2015) 56:649-58. doi: 10.1111/sjop.12257

32. Fontaine NM, Rijsdijk FV, McCrory EJ, Viding E. Etiology of different developmental trajectories of callous-unemotional traits. J Am Acad Child Adolesc Psychiatry. (2010) 49:656-64. doi: 10.1016/j.jaac.2010.03.014

33. Lynam DR, Charnigo R, Moffitt TE, Raine A, Loeber R, Stouthamer-Loeber M. The stability of psychopathy across adolescence. Dev Psychopathol. (2009) 21:1133-53. doi: 10.1017/S0954579409990083

34. Fanti KA, Kimonis E. Heterogeneity in externalizing problems at age 3: association with age 15 biological and environmental outcomes. Dev Psychol. (2017) 53:1230-41. doi: 10.1037/dev0000317

35. Dackis MN, Rogosch FA, Cicchetti D. Child maltreatment, callousunemotional traits, and defensive responding in high-risk children: an investigation of emotion-modulated startle response. Dev Psychopathol. (2015) 27:1527-45. doi: 10.1017/S0954579415000929

36. Fanti KA. Understanding heterogeneity in conduct disorder: a review of psychophysiological studies. Neurosci Biobehav Rev. (2018) 91:420. doi: 10.1016/j.neubiorev.2016.09.022

37. Kimonis ER, Fanti KA, Isoma Z, Donoghue K. Maltreatment profiles among incarcerated boys with callous-unemotional traits. Child Maltreat. (2013) 18:108-21. doi: 10.1177/1077559513483002

38. Kimonis ER, Frick PJ, Cauffman E, Goldweber A, Skeem J. Primary and secondary variants of juvenile psychopathy differ in emotional processing. Dev Psychopathol. (2012) 24:1091-103. doi: 10.1017/S0954579412000557

39. Bagley AD, Abramowitz CS, Kosson DS. Vocal affect recognition and psychopathy: converging findings across traditional and cluster analytic approaches to assessing the construct. J Abnorm Psychol. (2009) 118:38898. doi: 10.1037/a0015372

40. Hodgins S, Larm P, Ellenbogen M, Vitaro F, Tremblay RE. Teachers' ratings of childhood behaviours predict adolescent and adult crime among 3016 males and females. Can J Psychiatry. (2013) 58:14350. doi: 10.1177/070674371305800304

41. Hodgins S, Piatosa MJ, Schiffer B. Violence among people with schizophrenia: phenotypes and neurobiology. Curr Top Behav Neurosci. (2014) 17:32968. doi: 10.1007/7854_2013_259

42. Brennan PA, Mednick SA, Hodgins S. Major mental disorders and criminal violence in a Danish birth cohort. Arch Gen Psychiatry. (2000) 57:494500. doi: 10.1001/archpsyc.57.5.494

43. Hodgins S, Alderton J, Cree A, Aboud A, Mak T. Aggressive behaviour, victimization and crime among severely mentally ill patients requiring hospitalisation. $\mathrm{Br} \quad J$ Psychiatry.

(2007) 191:343-50. doi: 10.1192/bjp.bp.106.06.029587

44. Swanson JW, Swartz MS, van Dorn RA, Elbogen EB, Wagner HR, Rosenheck RA, et al. A national study of violent behavior in persons with schizophrenia. Arch Gen Psychiatry. (2006) 63:490-9. doi: 10.1001/archpsyc.63.5.490

45. Winsper C, Singh SP, Marwaha S, Amos T, Lester H, Everard L, et al. Pathways to violent behavior during first-episode psychosis: a report from the UK National EDEN Study. JAMA Psychiatry. (2013) 70:128793. doi: 10.1001/jamapsychiatry.2013.2445

46. Large MM, Nielssen O. Violence in first-episode psychosis: a systematic review and meta-analysis. Schizophr Res. (2011) 125:209-20. doi: 10.1016/j.schres.2010.11.026

47. Dean K, Laursen TM, Pedersen CB, Webb RT, Mortensen PB, Agerbo E. Risk of being subjected to crime, including violent crime, after onset of mental illness: a Danish national registry study using police data. JAMA Psychiatry. (2018) 75:689-96. doi: 10.1001/jamapsychiatry.2018.0534

48. Swanson JW, Belden CM. The link between mental illness and being subjected to crime in Denmark vs the United States: how much do poverty and the safety net matter? JAMA Psychiatry. (2018) 75:66970. doi: 10.1001/jamapsychiatry.2018.0528

49. Walker EF, Savoie T, Davis D. Neuromotor precursors of schizophrenia. Schizophr Bull. (1994) 20:441-51. doi: 10.1093/schbul/20.3.441

50. Welham J, Isohanni $M$, Jones $\mathrm{P}$, McGrath J. The antecedents of schizophrenia: a review of birth cohort studies. Schizophr Bull. (2009) 35:603-23. doi: 10.1093/schbul/sbn084

51. Dickson H, Laurens KR, Cullen AE, Hodgins S. Meta-analyses of cognitive and motor function in youth aged 16 years and younger who subsequently develop schizophrenia. Psychol Med. (2012) 42:74355. doi: 10.1017/S0033291711001693

52. Healy C, Brannigan R, Dooley N, Coughlan H, Clarke M, Kelleher I, et al. Childhood and adolescent psychotic experiences and risk of mental disorder: a systematic review and meta-analysis. Psychol Med. (2019) 49:158999. doi: 10.1017/S0033291719000485

53. Morgan C, Gayer-Anderson C, Beards S, Hubbard K, Mondelli V, Di Forti $\mathrm{M}$, et al. Threat, hostility and violence in childhood and later psychotic disorder: population-based case-control study. $\mathrm{Br} J$ Psychiatry. (2020) 217:575-82. doi: 10.1192/bjp.2020.133

54. Kim-Cohen J, Caspi A, Moffitt TE, Harrington H, Milne BJ, Poulton R. Prior juvenile diagnoses in adults with mental disorder: developmental follow-back of a prospective-longitudinal cohort. Arch Gen Psychiatry. (2003) 60:70917. doi: 10.1001/archpsyc.60.7.709

55. Hodgins S, Tiihonen J, Ross D. The consequences of conduct disorder for males who develop schizophrenia: associations with criminality, aggressive behavior, substance use, and psychiatric services. Schizophr Res. (2005) 78:323-35. doi: 10.1016/j.schres.2005.05.021

56. Hodgins S, Cree A, Alderton J, Mak T. From conduct disorder to severe mental illness: associations with aggressive behaviour, crime and victimization. Psychol Med. (2008) 38:975-87. doi: 10.1017/S0033291707002164

57. Hodgins S, Larm P, Molero-Samuleson Y, Tengström A, Larsson A. Multiple adverse outcomes over 30 years following adolescent substance misuse treatment. Acta Psychiatr Scand. (2009) 119:484-93. doi: 10.1111/j.1600-0447.2008.01327.x

58. Hodgins S, Larm P, Westerman J. Individuals developing schizophrenia are hidden among adolescent substance misusers. Psychol Med. (2016) 46:304150. doi: 10.1017/S0033291716001781

59. Krakowski M, Czobor P. Gender differences in violent behaviors: relationship to clinical symptoms and psychosocial factors. Am J Psychiatry. (2004) 161:459-65. doi: 10.1176/appi.ajp.161.3.459

60. Hodgins S, Riaz M. Violence and phases of illness: differential risk and predictors. Eur Psychiatry. (2011) 26:51824. doi: 10.1016/j.eurpsy.2010.09.006

61. Hodgins S. Aggressive behavior among persons with schizophrenia and those who are developing schizophrenia: attempting to understand the limited evidence on causality. Schizophr Bull. (2017) 43:1021-6. doi: 10.1093/schbul/sbx079

62. Hodgins S, Klein S. New clinically relevant findings about violence by people with schizophrenia. Can J Psychiatry. (2017) 62:86-93. doi: 10.1177/0706743716648300 
63. Krakowski M, Tural U et Czobor P. The importance of conduct disorder in the treatment of violence in schizophrenia: efficacy of clozapine compared with olanzapine and haloperidol. Am J Psychiatry. (2021) 178:26674. doi: 10.1176/appi.ajp.2020.20010052

64. Comai S, Tau M, Gobbi G. The psychopharmacology of aggressive behavior: a translational approach: part 1: neurobiology. J Clin Psychopharmacol. (2012) 32:83-94. doi: 10.1097/JCP.0b013e31823f8770

65. Schiffer B, Leygraf N, Müller BW, Scherbaum N, Forsting M, Wiltfang J, et al. Structural brain alterations associated with schizophrenia preceded by conduct disorder: a common and distinct subtype of schizophrenia? Schizophr Bull. (2013) 39:1115-28. doi: 10.1093/schbul/sbs115

66. McCutcheon RA, Reis Marques T, Howes OD. Schizophrenia-an overview. JAMA Psychiatry. (2020) 77:201-10. doi: 10.1001/jamapsychiatry.2019.3360

67. Moffitt TE, Caspi A, Rutter M, Silva PA. Sex Differences in Antisocial Behaviour. Cambridge University Press (2001).

68. Robitaille M-P, Checknita D, Vitaro F, Tremblay RE, Paris J, Hodgins S, et al. A prospective, longitudinal, study of men with borderline personality disorder with and without comorbid antisocial personality disorder. Borderline Personal Disord Emot Dysregul. (2017) 4:25. doi: 10.1186/s40479-017-0076-2

69. Mancke F, Herpertz SC, Bertsch K. Aggression in borderline personality disorder: a multidimensional model. Personal Disord. (2015) 6:27891. doi: 10.1037/per0000098

70. Hunt E, Bornovalova MA, Patrick CJ. Genetic and environmental overlap between borderline personality disorder traits and psychopathy: evidence for promotive effects of factor 2 and protective effects of factor 1. Psychol Med. (2015) 45:1471-81. doi: 10.1017/S0033291714002608

71. Karsten J, Vogel V de, Lancel M. Characteristics and offences of women with borderline personality disorder in forensic psychiatry: a multicentre study. Psychology, Crime \& Law. (2016) 22:224-37. doi: 10.1080/1068316X.2015.1077250

72. Newhill CE, Eack SM, Mulvey EP. Violent behavior in borderline personality. J Pers Disord. (2009) 23:541-54. doi: 10.1521/pedi.2009.2 3.6.541

73. Belsky DW, Caspi A, Arseneault L, Bleidorn W, Fonagy P, Goodman M, et al. Etiological features of borderline personality related characteristics in a birth cohort of 12-year-old children. Dev Psychopathol. (2012) 24:25165. doi: 10.1017/S0954579411000812

74. Wertz J, Caspi A, Ambler A, Arseneault L, Belsky DW, Danese A, et al. Borderline symptoms at age 12 signal risk for poor outcomes during the transition to adulthood: findings from a genetically sensitive longitudinal cohort study. J Am Acad Child Adolesc Psychiatry. (2020) 59:1165-77.e2. doi: 10.1016/j.jaac.2019.07.005

75. Beeney JE, Forbes EE, Hipwell AE, Nance M, Mattia A, Lawless JM, et al. Determining the key childhood and adolescent risk factors for future BPD symptoms using regularized regression: comparison to depression and conduct disorder. J Child Psychol Psychiatry. (2021) 62:22331. doi: $10.1111 /$ jcpp. 13269

76. Sariaslan A, Lichtenstein P, Larsson H, Fazel S. Triggers for violent criminality in patients with psychotic disorders. JAMA Psychiatry. (2016) 73:796803. doi: 10.1001/jamapsychiatry.2016.1349

77. Herndon RW, Iacono WG. Psychiatric disorder in the children of antisocial parents. Psychol Med. (2005) 35:1815-24. doi: 10.1017/S0033291705005635

78. Jaffee SR, Belsky J, Harrington H, Caspi A, Moffitt TE. When parents have a history of conduct disorder: how is the caregiving environment affected? $J$ Abnorm Psychol. (2006) 115:309-19. doi: 10.1037/0021-843X.115.2.309

79. Jaffee SR, Caspi A, Moffitt TE, Dodge KA, Rutter M, Taylor A, et al. Nature $\times$ nurture: genetic vulnerabilities interact with physical maltreatment to promote conduct problems. Dev Psychopathol. (2005) 17:6784. doi: 10.1017/S0954579405050042

80. Jaffee SR, Caspi A, Moffitt TE, Taylor A. Physical maltreatment victim to antisocial child: evidence of an environmentally mediated process. J Abnorm Psychol. (2004) 113:44-55. doi: 10.1037/0021-843X.113.1.44

Conflict of Interest: The author declares that the research was conducted in the absence of any commercial or financial relationships that could be construed as a potential conflict of interest.

Publisher's Note: All claims expressed in this article are solely those of the authors and do not necessarily represent those of their affiliated organizations, or those of the publisher, the editors and the reviewers. Any product that may be evaluated in this article, or claim that may be made by its manufacturer, is not guaranteed or endorsed by the publisher.

Copyright (C) 2022 Hodgins. This is an open-access article distributed under the terms of the Creative Commons Attribution License (CC BY). The use, distribution or reproduction in other forums is permitted, provided the original author(s) and the copyright owner(s) are credited and that the original publication in this journal is cited, in accordance with accepted academic practice. No use, distribution or reproduction is permitted which does not comply with these terms. 